\title{
Performance of IFAT, ELISA, direct parasitological examination and PCR on lymph node aspirates for canine visceral leishmaniasis diagnosis
}

Camargo JB (1), Langoni H (1), Troncarelli MZ (1), Machado JG (1), Lucheis SB (1, 2), Padovani CR (3)

(1) Department of Veterinary Hygiene and Public Health, School of Veterinary Medicine and Animal Husbandry, São Paulo State University (UNESP - Univ Estadual Paulista), Botucatu, São Paulo State, Brazil; (2) São Paulo Agency of Agribusiness Technology, APTA/SAA, Bauru, São Paulo State, Brazil; (3) Department of Biostatistics, Botucatu Bioscience Institute, São Paulo State University (UNESP - Univ Estadual Paulista), Botucatu, São Paulo State, Brazil.

\begin{abstract}
Canine visceral leishmaniasis $(\mathrm{CVL})$ is endemic in numerous Brazilian regions. The greatest difficulty in controlling the disease is the diagnostic limitation. In the present study, the most common tests employed for visceral leishmaniasis diagnosis were compared: immunofluorescence antibody test (IFAT), immunoenzymatic assay (ELISA), direct parasitological examination and polymerase chain reaction (PCR). Samples of lymph node aspirates and blood were collected from 100 dogs that lived in an endemic area (Bauru city, São Paulo state) and from 100 negative controls from a non-endemic area (Botucatu city, São Paulo state). Specificity of both IFAT and PCR was 100\% whereas ELISA was 99\%. Sensitivities were 97.77, 93.33 and $91.11 \%$ respectively for IFAT, ELISA and PCR.
\end{abstract}

Key words: visceral leishmaniasis, dog, diagnosis.

\section{INTRODUCTION}

Canine visceral leishmaniasis (CVL) is a global zoonosis. In South and Central America, the etiologic agent is the protozoan L. chagasi. Dogs are the main reservoirs in urban areas due to their close contact with humans and the high prevalence of the disease among these animals. Vectors are phlebotomine sand flies of the species Lutzomyia longipalpis, which proliferate in sites where organic matter is available. Control measures, in Brazil, basically involve the treatment of human cases, spraying of houses and nearby areas with residual insecticides and the identification and euthanasia of dogs that are serologically positive (1). Despite the strategies adopted, the disease continues to become more common in endemic areas (2). However, the main difficulty in controlling CVL is its diagnosis, which is based on antibody detection and consequently presents many limitations (3). The association of diagnostic methods may improve the detection of infection among canine populations. Positive dogs constitute reservoirs and sources of infection to humans and other animals, and thus are euthanized.

This study aimed to compare different techniques that would improve the CVL diagnosis. The combination of serological and parasitological techniques can raise the number of dogs diagnosed with the infection.

\section{MATERIALS AND METHODS}

The study was approved by the Ethics Committee in Animal Experimentation of the School of Veterinary Medicine and Animal Husbandry, UNESP, protocol n. 04/2006 CEEA.

\section{Samples}

Two hundred animals were tested: 100 dogs from the Zoonosis Control Center (ZCC) of Bauru, an endemic area for CVL, and 100 from 
the Municipal Cannel of Botucatu, a nonendemic area.

Blood samples were obtained by puncture of the cephalic vein and put in tubes without EDTA and centrifuged at $3,000 \mathrm{rpm}$ for 15 minutes. Sera were stored in $1.5-\mathrm{mL}$ microtubes at $-20^{\circ} \mathrm{C}$ serology. Fine-needle aspiration was carried out in popliteal lymph nodes and the smears were stained by Giemsa for direct parasitological examination. The smears were stored in boxes for later analyses. The remaining aspirates were maintained in sterile DNase- and RNase-free microtubes containing $1.5 \mathrm{~mL}$ of sterile phosphate buffered saline (PBS), $\mathrm{pH} 7.2$, and stored at $-20^{\circ} \mathrm{C}$ until the moment of DNA extraction for PCR.

\section{IFAT}

The immunofluorescence antibody test was performed according to Camargo (4), using $L$. major promastigote antigens. The first dilution was 1:40. Samples were considered positive when a reaction was observed at 1:40.

\section{ELISA}

ELISA was performed according to Voller et al. (5), using L. major antigen. Samples were diluted to $1: 80$ and the conjugate used was peroxidase-labeled canine anti-IgG, diluted to 1:6,000. Reaction was carried out using hydrogen peroxide and ortho-phenylenediamine (OPD), and observed in an ELISA reader using a 492$\mathrm{nm}$ filter. Results were expressed as optical density values. Cutoff value (CO) was calculated using the formula:

$$
\mathrm{CO}=\text { mean of negative controls } \times 2 \times 1.2
$$

where 2 and 1.2 are correction factors, according to the kit EIE-leishmaniose-visceral-canina-BioManguinhos $^{\circledast}$ (Bio-Manguinhos, Brazil).

\section{PCR}

Amersham Genomic Prep Cells and Tissue DNA Isolation kit $^{\oplus}$ (Sweden) was used in DNA extraction in a fixed sample volume of $250 \mu \mathrm{L}$, following the protocol for extraction of fluids.

The following reagents were used for the DNA amplification: $5 \mu \mathrm{L}$ of PCR buffer (Buffer 10x) $(50 \mathrm{mmol} \mathrm{KCl}, 10 \mathrm{mmol}$ of Tris- $\mathrm{HCl}), 1.5$ $\mathrm{U}$ of Taq-polymerase, $10 \mathrm{pmol}$ of each primer, $1.5 \mathrm{UI}$ of $\mathrm{MgCl}_{2}, 15.2 \mu \mathrm{L}$ of ultrapure water, 200 $\mathrm{mM}$ of oligonucleotides and $10 \mu \mathrm{L}$ of the sample. To confirm the species, positive dogs in these analyses [using genus-specific primers (PCRLIN)] were tested again with the species-specific primers RV1 and RV2 (PCR-RV). The primers

Table 1. Thermocycler conditions for amplification and characterization of the primers

\begin{tabular}{|c|c|c|}
\hline $\begin{array}{l}\text { Time and } \\
\text { temperature } \\
\text { conditions }\end{array}$ & LIN R4 and LIN 19 (5) & RV1 and RV2 (6) \\
\hline $\begin{array}{c}\text { Initial } \\
\text { denaturation } \\
\left({ }^{\circ} \mathrm{C}\right)\end{array}$ & 95 for 3 minutes & 94 for 4 minutes \\
\hline $\begin{array}{c}\text { Denaturation } \\
\left({ }^{\circ} \mathrm{C}\right)\end{array}$ & 95 for 30 seconds & 94 for 30 seconds \\
\hline $\begin{array}{c}\text { Annealing } \\
\left({ }^{\circ} \mathrm{C}\right)\end{array}$ & 58 for 30 seconds & 59 for 30 seconds \\
\hline $\begin{array}{c}\text { Extending } \\
\left({ }^{\circ} \mathrm{C}\right)\end{array}$ & 72 for 1 minute & 72 for 30 seconds \\
\hline $\begin{array}{l}\text { Number of } \\
\text { cycles }\end{array}$ & 32 & 40 \\
\hline $\begin{array}{l}\text { Final extending } \\
\left({ }^{\circ} \mathrm{C}\right)\end{array}$ & 72 for 7 minutes & 72 for 10 minutes \\
\hline Sequences & $\begin{array}{c}\text { LIN19 5' CAGAACGCCCCTACCCG3' } \\
\text { LINR4 5'GGGGTTGGTGTAAAATAGGG3' }\end{array}$ & $\begin{array}{l}\text { RV1 5'CTTTTCTGGTCCCGCGGGTAGG3' } \\
\text { RV2 5'CCACCTGGCCTATTTTACACCA3' }\end{array}$ \\
\hline $\begin{array}{l}\text { Product weight } \\
\text { (base pairs) }\end{array}$ & 720 & 145 \\
\hline
\end{tabular}


and amplification conditions are described in Table $1(6,7)$.

The amplified products were identified by electrophoresis at $80 \mathrm{~V}$ in $2.0 \%$ agarose gel containing $2 \mu \mathrm{L}$ of ethidium bromide (Figure 1). The PCR products were observed in an ultraviolet transilluminator, using a 300-nm filter.

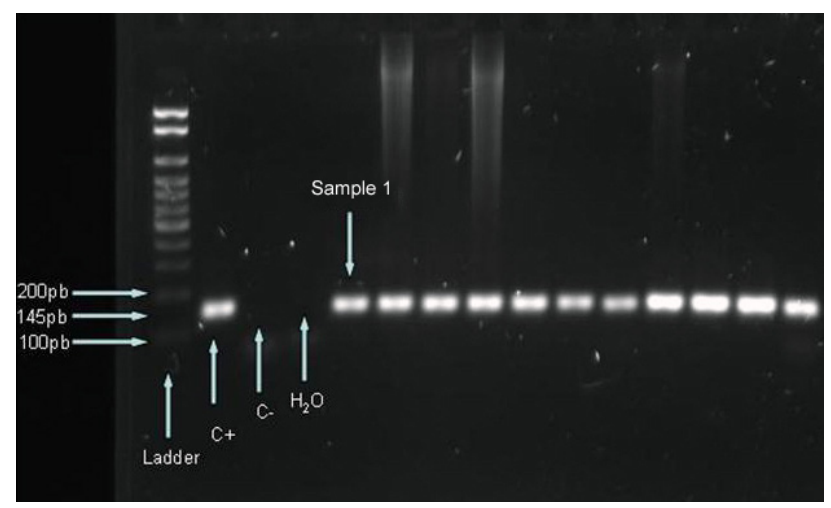

Figure 1. Gel electrophoresis presenting 145 base pair bands amplified by RV1 and RV2 primers.

C+: positive control (L. chagasi promastigotes); C-: negative control (sample from a non-endemic area); $\mathrm{H}_{2} \mathrm{O}$ : water; ladder.

\section{Statistical Analysis}

Sensitivity (S), specificity (SP), false negatives (FN), false positives (FP), true negatives (TN), true positives (TP), predictive positive values (PPV) and predictive negative values (PNV) were calculated using a $2 \times 2$ table (8). The parasitological examination of the lymph nodes was defined as the gold-standard test. Agreement between the tests was determined by the McNemar test $(p)(9)$.

\section{RESULTS}

The results of IFAT, ELISA and PCR were compared with direct parasitological test (goldstandard), specificity and sensitivity of the tests, as shown in Table 2. All samples from Botucatu were negative in all tests, except for ELISA, which showed one reactive sample (1\%).

Eighty-two dogs from Bauru were positive and 18 were negative by IFAT. Forty-five dogs were positive by the lymph node direct parasitological examination and 44 of them were also positive by IFAT. The distribution of IgG anti-Leishmania titers detected by IFAT are presented in Figure 2.

Positive predictive values were 100, 97.67 and $100 \%$ for IFAT, ELISA and PCR-LIN, respectively.
Negative predictive values were 99.01, 97.06 and $96.15 \%$ for IFAT, ELISA and PCR-LIN, respectively. Values of $p$ from the McNemar test are presented in Table 3. At 5\% significance level, the test results were less consistent than the direct parasitological (gold standard). This happens due to the inferior sensitivity of direct parasitological test, compared to other techniques.

Table 2. Results of IFAT, ELISA and PCR, compared with direct parasitological test (gold standard)

\begin{tabular}{c|c|c|c} 
& IFAT & ELISA & PCR \\
\hline True positives & 44 & 42 & 41 \\
\hline True negatives & 100 & 99 & 100 \\
\hline False positives & 0 & 1 & 0 \\
\hline False negatives & 1 & 3 & 4 \\
\hline Sensitivity & $97.78 \%$ & $93.33 \%$ & $91.11 \%$ \\
\hline Specificity & $100 \%$ & $99 \%$ & $100 \%$ \\
\hline Total & 145 & 145 & 145 \\
\hline
\end{tabular}

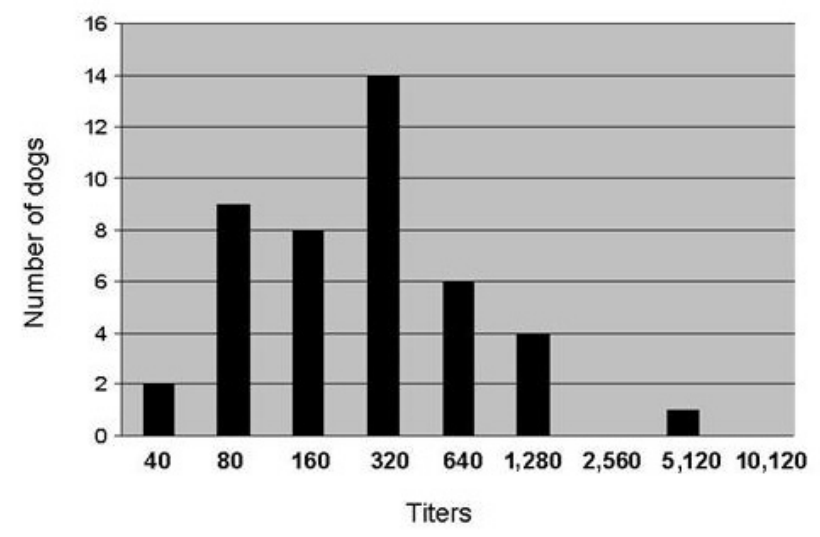

Figure 2. Distribution of IgG anti-Leishmania titers detected by IFAT in positive dogs $(n=44)$ from Bauru, SP, Brazil.

The respective concordance percentages between direct parasitological test and the other techniques are $61.0,59.0$ and $60.0 \%$ for IFAT, ELISA and PCR.

Four of the dogs negative by IFAT were positive by PCR-LIN. When the tests were used together, a large number of infected animals were detected. PCR and IFAT detected 86 dogs probably infected by Leishmania. In the present study, one dog from Bauru presented a false negative by IFAT, but showed parasites in the 
lymph nodes. Despite this, 77 dogs from Bauru were positive by PCR LIN, of which 36 of them $(46.75 \%)$ did not present any amastigote form in their lymph nodes.

Table 3. Number of animals positive and negative by IFAT, ELISA and PCR compared with the direct parasitological test and $p$ values (McNemar test)

\begin{tabular}{c|c|c|c|c|c|c}
\hline \multirow{2}{*}{$\begin{array}{c}\text { Parasitological } \\
\text { test }\end{array}$} & \multicolumn{2}{|c|}{ IFAT } & \multicolumn{2}{c|}{ ELISA } & \multicolumn{2}{c}{ PCR } \\
\cline { 2 - 7 }+ & + & - & + & - & + & - \\
\hline- & 44 & 1 & 42 & 3 & 41 & 4 \\
\hline \multirow{2}{*}{$\begin{array}{c}\text { McNemar test } \\
(p)\end{array}$} & $\begin{array}{c}33.23 ; \\
p<0.0001\end{array}$ & $\begin{array}{c}28.20 ; \\
p<0.0001\end{array}$ & $\begin{array}{c}24.03 ; \\
p<0.0001\end{array}$ \\
\hline
\end{tabular}

+ positive; - negative

\section{DISCUSSION}

Since whole Leishmania promastigotes are used as antigens in the routine assay, false-positive reactions are frequent due to cross-reaction with sera from other diseases, mainly Chagas disease $(10,11)$. Troncarelli et al. (12) analyzed serum samples from 200 dogs using IFAT and observed the occurrence of cross-reactions between Leishmania spp. and Trypanossoma cruzi (T. cruzi) in $16.5 \%$ (33) of them. Another study showed cross-reaction between T. cruzi and Leishmania spp. by IFAT in dogs suspected for CVL in Campo Grande, MS. Thus, the technique may identify a large number of false positives for CVL (13). Moreover, failure to seroconvert and IFAT false-positive and false-negative can all occur in Leishmania-infected dogs and; this fact can change sensitivity and specificity of tests (14). Immunodeficiency and the inability of some patients to produce detectable amounts of antibodies may have been the cause of positive PCR and negative IFAT results.

In the study by Ikonomopoulos et al. (6), samples of several tissues and serum of suspect dogs were tested for visceral leishmaniasis by IFAT, PCR and direct microscopic examination. Agreement between IFAT and PCR of blood samples was $91.8 \%$ (147/160 cases). Discrepancy was greater in IFAT-positive samples, which may be attributed to the persistence of antibodies even after PCR-detectable DNA has been eliminated.
Moreover, they verified that 14 of 34 dogs negative by direct examination were positive by PCR LIN and this fact can be due to the low detection rate of the direct examination. Despite the high PCR accuracy, in some instances this test also can fail and reveal false negatives. In the study by Maia et al. (15), 95 cultures and PCR assays were carried out in lymph node aspirates, with 69 negative and 23 positive samples. None of the samples that were negative in culture were positive by PCR. However, three of them were positive in culture but negative by PCR. Despite the lower sensitivity of direct parasitological examination when compared with culture, these results were similar to the ones obtained in the present study, as four PCR-negative dogs showed amastigote forms in the smears from lymph node aspirates (16). Based on these statements, the improvement in CVL diagnosis depends on the association of techniques.

One dog was negative by IFAT and positive by PCR, while two dogs were negative by ELISA and positive by PCR. Similarly, Manna et al. (17) investigated 95 dogs infected by L. chagasi and observed that $81(85.2 \%)$ reacted to IFAT and were PCR-positive, whereas 14 (14.73\%) dogs were negative by IFAT and positive by PCR of lymph nodes. Leontides et al. (18) found that in a total of 73 healthy hunting dogs living in an endemic region, PCR found 46 positives (63\%), versus only nine by IFAT (12.3\%). These data clearly demonstrate that most of the dogs residing in endemic areas became infected but usually remained seronegative.

The agreement found between the gold standard and the other tests in this study is considered low, due to its low sensitivity compared to other tests, which indicates using them concomitantly. The use of the direct test together with a serological test or PCR contributes to the detection of infected animals and confirms the infection in doubtful cases (19).

Andrade et al. (19) detected that $62.5 \%$ of infected animals were initially classified as noninfected by routine diagnostic tests for CVL (direct microscopy and IFAT). These authors also stated that methods used in endemic areas underestimate the number of animals that are actually infected (false negatives) and remain as reservoirs. In the present study, only one dog in Bauru was negative both by IFAT and ELISA, but positive by PCR, indicating that the 
latter method is useful in identifying infected animals that would otherwise go undetected by serological tests. Since PCR is able to identify subclinical cases, its utilization together with serology is valuable for determining the extent of subclinical infections, and for estimating the number of dogs that should be targeted for control measures.

Protozoan species identification in seropositive dogs from endemic areas is very important, especially given the possibility of co-infections, which reinforces the necessity of reviewing the most common methods employed for epidemiological control. Madeira et al. (20) reported the first case of co-infection by L. braziliensis and L. chagasi in Rio de Janeiro. Species-specific primers were used and no mixed infections were detected in the skin, spleen or lymph node lesions, suggesting that the species has specific tropism, even when co-infection occurs. Therefore, the examination of animal samples from different organs that present cutaneous lesions is a crucial step. Other studies demonstrated the occurrence of co-infection with viscerotropic and cutaneous species in areas previously considered endemic only for $L$. braziliensis or for L. chagasi $(3,19,20)$.

Dogs affected by cutaneous leishmaniasis may also be found positive by serological tests, underscoring the importance of a speciesspecific PCR. Human patients infected by $L$. chagasi showed positive results when $L$. braziliensis and T. cruzi antigens were used in immunofluorescence, which indicates that these parasites may have common antigenic determinants (21).

Since Bauru is also an endemic region for cutaneous leishmaniasis, positive PCR-LIN animals were tested again using the speciesspecific primers RV1 and RV2 in order to confirm the infection by L. chagasi. All 41 dogs positive by PCR-LIN were also positive by PCR-RV, indicating that these animals were actually infected by $L$. chagasi. However, the hypothesis of co-infection by both species was not discarded. Despite this, it is important to reinforce that in visceral leishmaniasis cases, titers are normally high, generally over 80 , so that lower titers should be confirmed by other methods. In the present study, the two dogs that showed a titer of 40, and six of the eight dogs that showed a titer of 80 were positive by PCR-RV, confirming infection by L. chagasi.

\section{CONCLUSION}

Sensitivity and specificity of IFAT, ELISA and PCR in the present study were elevated, indicating that these techniques may be used in CVL diagnosis. PCR was able to diagnose serologically negative dogs, thus improving and aiding the identification of reservoirs, and contributing to CVL control.

The culling of dogs is one of the methods recommended by the Brazilian Ministry of Health and the WHO for controlling the endemic status of leishmaniasis in the country. Moreover, euthanasia is indicated for all dogs positive by IFAT. Therefore, correct diagnosis of infected dogs is extremely important for the success of the disease control program. The use of more than one technique, not only serological tests, may improve the detection of affected animals. According to the present results, the assessment of the infection should associate a parasitological test - such as PCR, which presents good sensitivity and specificity - with an immunological test such as ELISA or IFAT, used routinely to detect antibodies against the disease.

\section{ACKNOWLEDGEMENTS}

The authors are grateful to Professor João Pessoa Araújo Júnior for hosting part of the study in the Laboratory of Virology and Molecular Diagnosis, to the technicians and veterinarians of the Zoonosis Control Center in Bauru and the Municipal Shelter in Botucatu, to The State of São Paulo Research Foundation (FAPESP) for the Masters degree grant and for the research support grant.

\section{COPYRIGHT \\ (C) CEVAP 2010}

\section{SUBMISSION STATUS}

Received: October 8, 2009.

Accepted: February 2, 2010.

Abstract published online: February 12, 2010.

Full paper published online: August 31, 2010.

\section{CONFLICTS OF INTEREST}

There is no conflict.

\section{FINANCIAL SOURCE}

The State of São Paulo Research Foundation (FAPESP) provided the Masters degree grant 
(process n. 2005/3236-9) and the research support grant (process n. 2006/06565-6).

\section{ETHICS COMMITTEE APPROVAL}

The present study was approved by the Ethics Committee in Animal Experimentation of the School of Veterinary Medicine and Animal Husbandry, UNESP, protocol n. 04/2006 CEEA.

\section{CORRESPONDENCE TO}

JANAINA BIOTTO CAMARGO, Departamento de Higiene Veterinária e Saúde Pública, Faculdade de Medicina Veterinária e Zootecnia, UNESP, Distrito de Rubião Júnior, s/n, Botucatu, SP, 18.618-000, Brazil. Phone: +55 1438116270 . Fax: 55143811 6075. Email: jbiotto@yahoo. com.br.

\section{REFERENCES}

1. Brasil. Fundação Nacional da Saúde. Leishmaniose visceral (Calazar). In: Brasil. Fundação Nacional da Saúde, editor. Guia vigilância epidemiológica. Brasília: FUNASA; 2006. p. 527-39.

2. D'Andrea LAZ, Camargo-Neves VLF, Sampaio SMP, Kronka SN, Sartor IF. American visceral leishmaniasis: disease control strategies in Dracena microregion in Alta Paulista, SP, Brazil. J Venom Anim Toxins incl Trop Dis. 2009;15(2):305-24.

3. Gomes AHS, Ferreira IMR, Lima MLSR, Cunha EA, Garcia AS, Araújo MFL, et al. PCR identification of Leishmania in diagnosis and control of canine leishmaniasis. Vet Parasitol. 2006;144(3-4):23441.

4. Camargo ME. Fluorescent antibody test for the serodiagnosis of American trypanosomiasis. Technical modification employing preserved culture forms of Trypanosoma cruzi in a slide test. Rev Inst Med Trop São Paulo. 1966; 8(5):227-34.

5. Voller A, Bidwell DE, Bartlett A. Enzyme linked immunoassays in diagnostic medicine. Theory and practice. Bull World Health Organ. 1976;53(1):55-65.

6. Ikonomopoulos J, Kokotas S, Gazouli M, Zavras A, Stoitsiou M, Gorgoulis VG. Molecular diagnosis of leishmaniasis in dogs. Comparative application of traditional diagnostic methods and the proposed assay on clinical samples. Vet Parasitol. 2003;113(2):99-113.

7. Lachaud L, Machergui-Hammami S, Chabbert E, Dereure J, Dedet JP, Bastien P. Comparison of six PCR methods using peripheral blood for detection of canine visceral leishmaniasis. J
Clin Microbiol. 2002;40(1):210-5.

8. Pagano M, Gauvreau K. Principles of biostatistics. $2^{\text {nd }}$ ed. Pacific Grove: Duxbury Press; 2000.

9. Norman GR, Streiner DL. Bioestatistics: the bare essentials. St Louis: Mosby Year Book; 1994. $260 \mathrm{p}$.

10. Celeste BJ, Angel SO, Castro LG, Gidlund M, Goto H. Leishmania Infantum heat shock protein 83 for the serodiagnosis of tegumentary leishmaniais. Braz J Med Biol Res. 2004;37(11):1591-3.

11. Ribeiro FC, de O Schubach A, Mouta-Confort E, Schubach TM, de Fátima Madeira M, Marzochi MCA. Use of ELISA employing Leishmania (Viannia) braziliensis and Leishmania (Leishmania) chagasi antigens for the detection of IgG and IgG1 and IgG2 subclasses in the diagnosis of American tegumentary leishmaniasis in dogs. Vet Parasitol. 2007;148(3-4):200-6

12. Troncarelli MZ, Camargo JB, Machado JG, Lucheis SB, Langoni H. Leishmania spp. and/ or Trypanossoma cruzi diagnosis in dogs from endemic and non-endemic areas for canine visceral leishmaniasis. Vet Parasitol. 2009;164(24):118-23.

13. Eloy LJ, Tome RO, Langoni $\mathrm{H}$, Lucheis SB. Cross-reaction between Trypanossoma cruzi and Leishmania sp. by the indirect immunofluorescence assay (IFAT) in dogs suspected to visceral leishmaniasis. J Venom Anim Toxins incl Trop Dis. 2008;14(4):832.

14. Rosypal AC, Gogal Jr RM, Zajac AM, Troy GC, Lindsay DS. Flow cytometric analysis of cellular immune responses in dogs experimentally infected with a North American isolate of Leishmania infantum. Vet Parasitol. 2005;131(12):45-51.

15. Maia C, Ramada J, Cristóvão JM, Gonçalves L, Campino L. Diagnosis of canine leishmaniasis: conventional and molecular techniques using different tissues. Vet J. 2009;179(1):142-4.

16. Mancianti F, Meciani N. Specific serodiagnosis of canine leishmaniasis by indirect immunofluorescence, indirect hemagglutination, and counterimmunoelectrophoresis. Am J Vet Res. 1988;49(8):1409-11.

17. Manna L, Vitale F, Reale S, Caracappa S, Pavone LM, Morte RD, et al. Comparison of different tissue sampling for PCR-based diagnosis and follow-up of canine visceral leishmaniasis. Vet Parasitol. 2004;125(3-4):251-62.

18. Leontides LS, Saridomichelakis MN, Billinis C, Kontos V, Koutinas AF, Galatos AD, et al. A crosssectional study of Leishmania spp. infection in clinically healthy dogs with polimerase chain reaction and serology in Greece. Vet Parasitol. 2002;109(1-2):19-27. 
19. Andrade HM, Reis AB, dos Santos SL, Volpini AC, Marques MJ, Romanha AJ. Use of PCR-RFLP to identify Leishmania species in naturally-infected dogs. Vet Parasitol. 2004;140(3-4):231-8.

20. Madeira MF, Schubach A, Schubach TMP, Pacheco RS, Oliveira FS, Pereira SA, et al. Mixed infection with Leishmania (Viannia) braziliensis and Leishmania (Leishmania) chagasi in a naturally infected dog from Rio de Janeiro, Brazil. Trans Royal Soc Trop Med Hyg. 2006;100(5):442-5.

21. Vexenat A de C, Santana JM, Teixeira AR. Crossreactivity of antibodies in human infections by the kinetoplastid protozoa Trypanosoma cruzi, Leishmania chagasi and Leishmania (Viannia) braziliensis. Rev Inst Med Trop São Paulo. 1996;38(3):177-85. 